\title{
Challenges Associated with Site Response Analyses for Soft Soils Subjected to High-Intensity Input Ground Motions
}

\author{
Shawn C. Griffiths ${ }^{a}$, Brady R. Cox ${ }^{b *}$, Ellen M. Rathje ${ }^{\mathrm{b}}$ \\ ${ }^{\mathrm{b}}$ Department of Civil and Architectural Engineering, University of Wyoming, Dept. 3295, 1000 E. University Ave. Laramie, WY, USA \\ 82071 \\ ${ }^{\mathrm{b}}$ Department of Civil, Architectural and Environmental Engineering, The University of Texas, 301 E Dean Keeton Stop C1792, Austin, \\ TX, USA 78712 \\ * Corresponding author. Tel.: 512471 9162, Email address: brcox@utexas.edu
}

\begin{abstract}
Nonlinear site response analyses are generally preferred over equivalent linear analyses for soft soil sites subjected to high-intensity input ground motions. However, both nonlinear (NL) and equivalent linear (EQL) analyses often result in large shear strain estimates (3-10\%) at soft sites, and these large strains may generate unusual characteristics in the predicted surface ground motions, such as irregular time histories and atypical spectral shapes. One source of unusual ground motion predictions may be attributed to unrealistically low shear strengths implied by commonly used modulus reduction curves. Therefore, modulus reduction and damping curves can be modified at shear strains greater than approximately $0.1 \%$ to provide a more realistic soil model for site response. However, even after these modifications, nonlinear and equivalent linear site response analyses still may generate unusual surface acceleration time histories and Fourier amplitude spectra at soft soil sites when subjected to highintensity input ground motions. In this study, we use equivalent linear and nonlinear 1D site response analyses for the well-known Treasure Island site to demonstrate challenges associated with accurately modeling large shear strains, and subsequent surface response, at soft soil sites.
\end{abstract}

keywords: Dynamic soil properties, Nonlinear site response analysis, Equivalent linear site response analysis, Soft soils, Earthquake

\section{Introduction}

One dimensional (1D) site response analyses are typically utilized to predict the amplification and/or attenuation of seismic ground motions by modeling the propagation of shear waves as they travel from bedrock to the ground surface. These analyses help to quantify the effects of local soil conditions on shaking intensities, and ultimately yield surface time histories and response spectra necessary for structural and geotechnical design. When 1D site response analyses are conducted for soft soil sites subjected to high-intensity input ground motions, large shear strains (3-10\%) are often predicted within the soil column. These large shear strains exceed the range where dynamic soil properties (i.e., shear modulus, G, and damping ratio, D) have been determined most reliably, and often approach or exceed values that are associated with shear failure of the soil. For example, the normalized shear modulus reduction $\left(\mathrm{G} / \mathrm{G}_{\max }\right)$ and damping relationships published by Darendeli [1] were based on limited data at shear strains greater than $0.1 \%$ and no data at shear strains greater than $0.6 \%$, as shown in Figure 1. Similar maximum shear strain levels exist in the databases used by others to develop dynamic soil property relationships, including Seed and Idriss [2], Hardin and Drenevich [3], and the Electric Power Research Institute (EPRI) [4]. Even the dataset for soft, fine-grained soils compiled by Vucetic and Dobry [5] only contains measurements of $\mathrm{G} / \mathrm{G}_{\max }$ and damping up to shear strains of approximately $1.0 \%$. The lack of dynamic soil data at large shear strains necessitates the extrapolation of dynamic soil 
properties to values beyond their initial published bounds when performing site response for soft soils subjected to high-intensity input ground motions. These extrapolations may yield implied shear strengths that are either too high or too low relative to the estimated, or measured, static shear strength of the soil. To address this issue, Stewart and Kwok [6] and Yee et al. [7] proposed methods for modifying the $\mathrm{G} / \mathrm{G}_{\max }$ curve at large shear strains to more realistically represent soil shear strength. These modifications can be used to produce $\mathrm{G} / \mathrm{G}_{\max }$ curves that more realistically represent the static shear strength of the soil at shear strains greater than $1.0 \%$. Hashash et al. [8] incorporated the $G / G_{\max }$ modifications of Stewart and Kwok [6] within a nonlinear stress-strain framework to develop G/G $G_{\max }$ and damping cures appropriate for nonlinear site response analyses. Site response analyses conducted with modified $\mathrm{G} / \mathrm{G}_{\max }$ curves are believed to produce more reliable estimates of shear strain and ground shaking. However, even after these modifications, nonlinear and equivalent linear site response analyses may still generate unusual surface acceleration time histories and Fourier amplitude spectra.
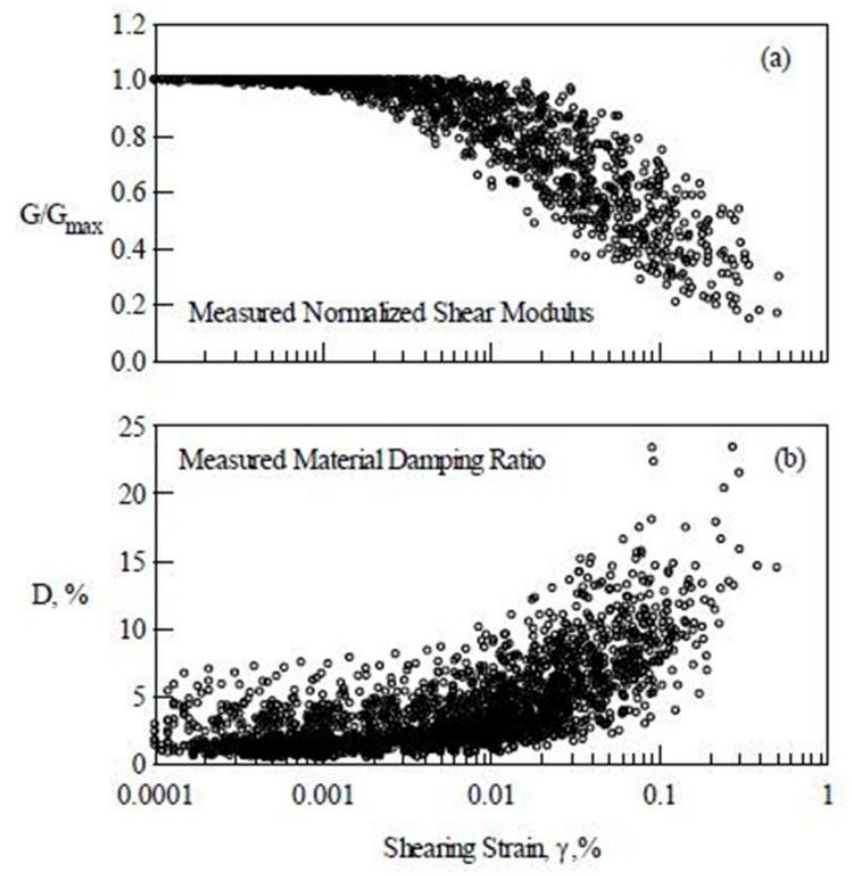

Figure 1. Modulus reduction and damping data from Darendeli [1].

This paper describes 1D site response analyses conducted for the Treasure Island site in California. The motivation for this research stems from problems encountered by practitioners and researchers when attempting to perform site response analyses for soft soil sites subjected to high intensity input design ground motions. Specifically, the analyses presented herein are used to: (1) investigate the problems encountered with modeling high intensity input ground motions at soft soil sites, (2) explore the influence of modifications to the large strain dynamic soil properties on the induced shear strains and predicted surface motions, and (3) critically evaluate the surface ground motions predicted from both nonlinear (NL) and equivalent linear (EQL) analyses before and after modifying the dynamic soil properties. Based upon previous observations and soil characteristics, the Treasure Island site is likely to exhibit liquefaction during strong earthquake events. While it is recognized that nonlinear effective stress site response analyses using a pore water pressure generation model could be used to analyze the coupled site amplification and liquefaction responses, the focus of this study was to investigate/compare the dynamic response results from EQL and NL analyses in a manner as similar as 
possible. Hence, the added complexities/uncertainties associated with nonlinear effective stress analyses and pore water pressure generation models have not been included for any of the analyses presented.

\section{Modification of Dynamic Soil Properties at Large Shear Strains}

Dynamic site response analyses at soft soil sites may require estimates of shear modulus (G) and damping ratio (D) over a shear strain range spanning four orders of magnitude (i.e., $<10^{-3} \%$ to $10 \%$ ). The variation of these dynamic properties with strain are defined using a $G / G_{\max }$ curve (where $G_{\max }$ is the maximum shear modulus at small strains) and a damping curve. While static soil properties such as shear strength are routinely measured at shear strains well above $1.0 \%$, dynamic soil property curves commonly are measured up to only moderate shear strains (i.e., $0.3 \%$ to $1.0 \%$ ). Theoretically, dynamic and static testing methodologies should be able to be combined to model the entire stress-strain behavior of the soil, but this has proven difficult in practice because static tests optimized to obtain shear strength estimates are not good at obtaining accurate shear modulus measurements at smaller strains, and viceversa. Thus, the commonly utilized $\mathrm{G} / \mathrm{G}_{\max }$ curves obtained from dynamic testing have historically been extrapolated to larger shear strains without consideration for the shear strength implied by the large strain portion of the curve.

The shear stress $(\tau)$ as a function of shear strain $(\gamma)$ can be obtained from a normalized $G / G_{\max }$ curve, the in-situ Vs, and the soil mass density $(\rho)$ according to:

$$
\tau=\gamma \cdot G=\gamma \cdot\left(G / G_{\max }\right) \cdot V_{S}^{2} \cdot \rho
$$

Eq. 1

When this relationship is extrapolated to large shear strains, a shear strength is implied at strains where failure is typically defined in static testing (i.e., 3-5\%). This implied shear strength may or may not be realistic relative to expected soil behavior.

Examples of $\mathrm{G} / \mathrm{G}_{\max }$ curves that have been extrapolated to $10 \%$ shear strain are presented in Figure 2. The following properties/parameters are assumed for this sandy soil layer: an effective friction angle of $33^{\circ}$, a shear wave velocity (Vs) of $150 \mathrm{~m} / \mathrm{s}$, an over consolidation ratio (OCR) of 1.0, a coefficient of uniformity $\left(\mathrm{C}_{\mathrm{u}}\right)$ of 3.0, a vertical effective stress $\left(\sigma^{\prime}{ }_{\text {vo }}\right)$ of $58.4 \mathrm{kPa}$, and a $\mathrm{K}_{\mathrm{o}}$ value of 0.5 . This information was used to develop appropriate $\mathrm{G} / \mathrm{G}_{\max }$ curves using four common relationships. Here, each relationship has been extrapolated beyond its approximately $0.3 \%-1 \%$ data limits to a shear strain of $10 \%$. The $\mathrm{G} / \mathrm{G}_{\max }$ curves of Seed and Idriss [2] and EPRI [4] were simply extrapolated to larger strains along a hyperbolic trend, while the Darendeli [1] and Menq [9] relationships are defined by equations that can be easily extrapolated to shear strains of $10 \%$, even though they are not constrained by data at such large shear strains.

Figure $2 \mathrm{~b}$ shows the shear stress versus shear strain curves implied by each extrapolated $\mathrm{G} / \mathrm{G}_{\max }$ relationship according to Eq. 1. Also shown is the estimated Mohr-Coulomb shear strength $(\tau)$ of 38 $\mathrm{kPa}$, which was calculated using the vertical effective stress $\left(\sigma^{\prime}{ }_{\text {vo }}\right)$ and the effective friction angle $\left(\phi^{\prime}\right)$ of $33^{\circ}$ of the soil according to:

$$
\tau=\sigma^{\prime}{ }_{v o} \tan \left(\phi^{\prime}\right)
$$

These commonly used $\mathrm{G} / \mathrm{G}_{\max }$ relationships imply shear strengths, at approximately $3 \%$ shear strain, which range from $15-40 \mathrm{kPa}$. In this case, only the extended $\mathrm{G} / \mathrm{G}_{\max }$ curve of Menq [9] provides a realistic estimate of the static shear strength relative to the friction angle. Note that the implied shear 
strength of the Seed and Idriss [2] curve would not change as a function of confining pressure, thus potentially over- or under-estimating shear strength depending on the depth. Furthermore, in this case, the shear strength implied from the $\mathrm{G} / \mathrm{G}_{\max }$ relationship published by Darendeli [1] is only $55 \%$ of the Mohr-Coulomb estimate of shear strength. Chui et al. [10] documented a similar trend when comparing measured shear strengths with the shear strengths implied from the $G / G_{\max }$ relationship of Darendeli [1] at shallow depths. However, it must be stressed that the curves have been extended approximately two orders of magnitude beyond the maximum shear strains in the database, as shown in Figure 1, so this is not unexpected. When $\mathrm{G} / \mathrm{G}_{\max }$ curves do not accurately represent the static shear strength at large shear strains, the $\mathrm{G} / \mathrm{G}_{\max }$ curves can be modified to better-represent the measured, or estimated, shear strengths.

Stewart and Kwok [6] developed a procedure that can be used to match the standard $\mathrm{G} / \mathrm{G}_{\max }$ curve at small shear strains, while gradually increasing the $\mathrm{G} / \mathrm{G}_{\max }$ at larger shear strains such that the target strength is reached. Yee et al. [7] further advanced this procedure to provide a systematic way to modify the $\mathrm{G} / \mathrm{G}_{\max }$ backbone curve to obtain a realistic shear strength. Modified $\mathrm{G} / \mathrm{G}_{\max }$ curves can easily be incorporated into EQL site response analyses, but cannot be directly used in nonlinear site response analyses because they cannot be represented by a single hyperbola. Hashash et al. [8] recommended a procedure that identifies nonlinear stress-strain parameters that fit the modified $\mathrm{G} / \mathrm{G}_{\max }$ curve, as well as the target damping curve, simultaneously. This procedure takes advantage of the modulus reduction and damping curve fitting procedure (MRDF), developed by Phillips and Hashash [11], which matches the target $\mathrm{G} / \mathrm{G}_{\max }$ curve over the entire strain range without large overestimation of the D curve. The MRDF curve fitting procedure modifies the hysteretic loading and unloading rules using a strain-dependent reduction factor to better model the cyclic response at large shear strains while maintaining a relatively simple expression. Prior to the development of the MRDF curve fitting procedure, slight adjustments in the $\mathrm{G} / \mathrm{G}_{\max }$ curve would cause a large overestimation of the $\mathrm{D}$ curve in NL analyses.
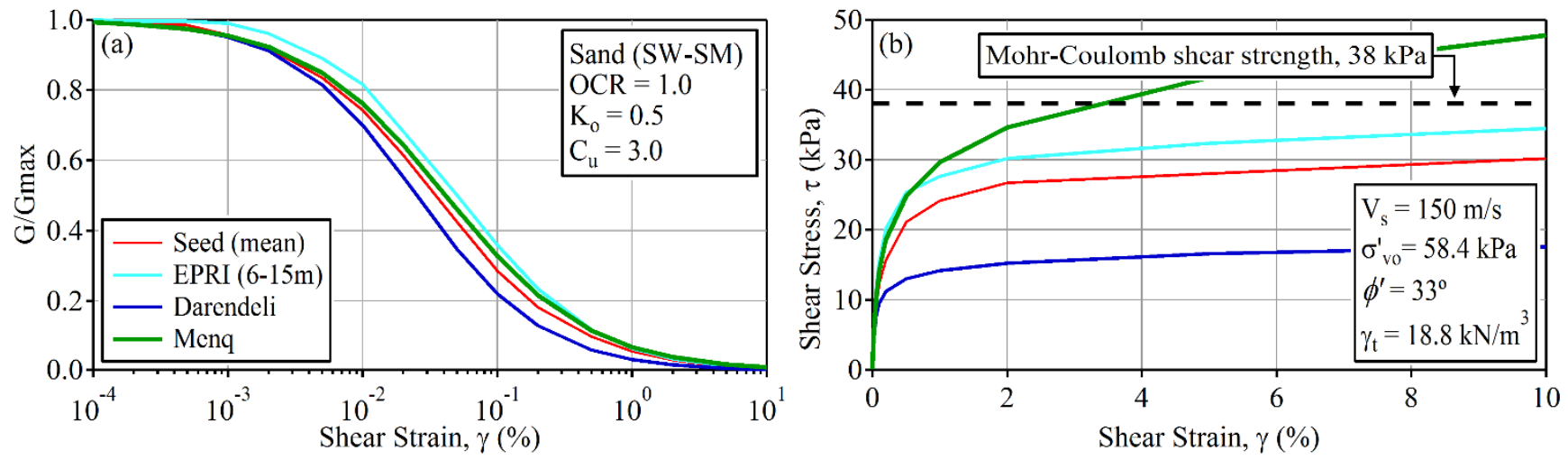

Figure 2. (a) Modulus reduction curves for a well graded sandy soil with silt from Seed and Idriss [2], EPRI [4], Darendeli [1] and Menq [9], each of which has been extended to $10 \%$ shear strain from the published maximum shear strains of $0.3 \%$ to $1.0 \%$ in their databases and (b) associated shear stress implied by the modulus reduction curves in comparison with the Mohr-Coulomb shear strength.

The Hashash et al. [8] fitting procedure is illustrated in Figure 3 using the same sandy soil discussed in Figure 2. The initial target $\mathrm{G} / \mathrm{G}_{\max }$ curve (Figure 3a), prior to modification to account for sher strength, is based on the relationship published by Darendeli [1]. After the initial target $\mathrm{G} / \mathrm{G}_{\max }$ curve is obtained, it is manually adjusted at shear strains greater than $0.1 \%$ so that the shear stresses 
better approximate the target static shear strength at a shear strain between $3 \%$ and 5\% (Figure $3 \mathrm{~b}$ ). The manually adjusted $\mathrm{G} / \mathrm{G}_{\max }$ curve, along with the original damping curve, are then used as target curves to determine stress-strain model parameters generated using the MRDF curve fitting procedure, as implemented in the site response program DEEPSOIL [12]. The process of manual adjustment and MRDF curve fitting is repeated until the MRDF stress-strain model parameters represent the target $\mathrm{G} / \mathrm{G}_{\max }$ curve, as well as the corresponding shear stress-shear strain curve, that matches the static shear strength at the desired shear strain. The final MRDF fit to the manually adjusted $\mathrm{G} / \mathrm{G}_{\max }$ curve is termed the strength corrected $\mathrm{G} / \mathrm{G}_{\max }$ curve. It is important to note that seemingly small adjustments in the $\mathrm{G} / \mathrm{G}_{\max }$ curve can translate into large differences in the implied shear strength (Figures $3 \mathrm{a}$ and $3 \mathrm{~b}$ ).

Modifications can also be made to the damping curve at large strains where little damping data are available (Figure 1). Unlike the case for $\mathrm{G} / \mathrm{G}_{\max }$, there is no target damping at large strains derived from strength testing or other means. One alternative is to cap the large strain damping at 15\% (Figure 3c) because few damping values greater than $15 \%$ have been measured (Figure 1). This approach also avoids over damping and it has been utilized in other studies, including Chiu et al. [9]. However, while capping damping near $15 \%$ may be conservative for design purposes, it should be noted that at least one laboratory study has revealed soil damping ratios well in excess of $15 \%$ at high shear strains (Hsu and Vucetic [13]). Therefore, more laboratory testing is needed at high shear strains to further inform these decisions in practice.

Within the site response program DEEPSOIL [12], the MRDF curve fitting procedure includes two different options for calculating the damping parameters: (1) MRDF-Darendeli, which allows the damping curve to decrease below some maximum value at large shear strains, and (2) MRDF-UIUC, which does not allow the damping value to decrease at large shear strains. The MRDF-UIUC model was used in this work, and was even flexible enough to handle modified versions of damping curves that were capped at $15 \%$. The ability of the MRDF model to replicate the target damping curve of Darendeli [1] at small shear strains and follow a smooth transition to a maximum damping value of $15 \%$ at larger shear strains (Figure 3c) demonstrates the versatility of the MRDF curve fitting method.
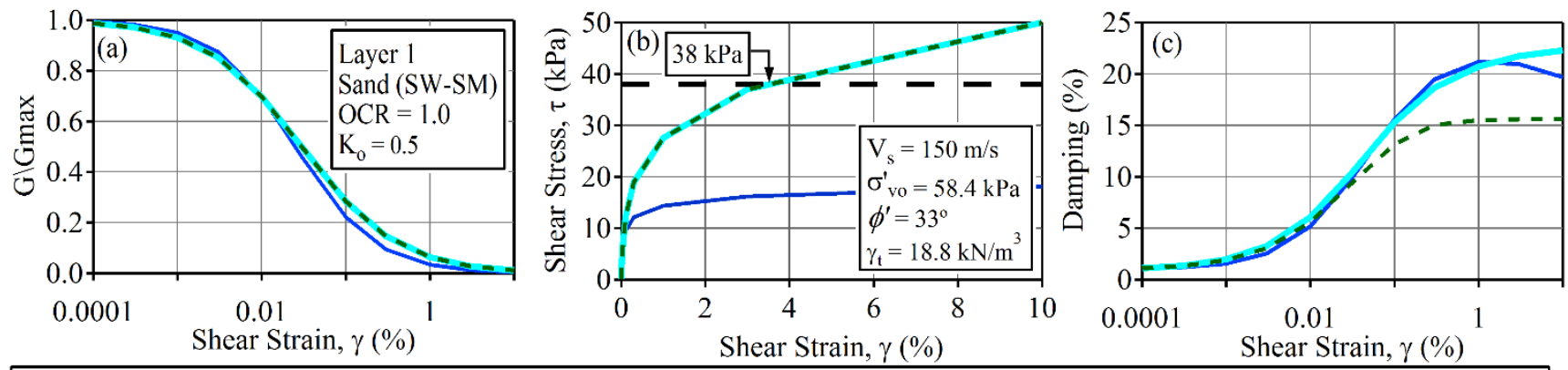

Initial Darendeli

Strength corrected

- - S Strength corrected, max damping $15 \%$

- Mohr-Coulumb shear strength

Figure 3. Dynamic soil properties for a sandy soil: (a) initial $G / G_{\max }$ curve from Darendeli [1] with strength corrected $\mathrm{G} / \mathrm{G}_{\max }$ curves, (b) corresponding implied shear strength for each of the $\mathrm{G} / \mathrm{G}_{\max }$ curves and, (c) damping curves from the MRDF UIUC curve fitting procedure with and without damping capped at $15 \%$.

\section{Site Description and Input Ground Motions}

Treasure Island (TI) was chosen as the site for this study due to the well documented site investigations, the presence of soft soils, and the high-intensity design ground motions resulting from its 
proximity to multiple faults capable of large magnitude earthquakes. In short, the TI site represents a typical soft soil site that could pose a challenge to those attempting to accurately perform 1D site response analyses for seismic design.

\subsection{Site Description}

Treasure Island is a 400 acre, man-made island in San Francisco Bay, located between San Francisco and Oakland, California. The shear wave velocity (Vs) profile and other soil data used for this study were obtained from Dickenson [14] and Pass [15], and are summarized in Figure 4. The site consists of a soft layer of well-graded sand with silt (SW-SM) from the surface to a depth of $13 \mathrm{~m}$, beneath which Young San Francisco Bay Mud $(\mathrm{CH})$ continues to a depth of $29 \mathrm{~m}$. These layers overlie a stiffer $12 \mathrm{~m}$ thick silty sand layer (SM) and a layer of Old Bay Clay (CL), which extends from $41 \mathrm{~m}$ to $91 \mathrm{~m}$ with an inclusion of well graded sand (SW) between $76 \mathrm{~m}$ and $81 \mathrm{~m}$. The soil profile was divided into nine major layers, as shown in Figure 4. These major layers were further divided into sublayers which were all assigned the same dynamic soil properties as the main layer. The sublayer thicknesses were chosen so that numeric filtering below $50 \mathrm{~Hz}$ would not be problematic during site response analyses. Input ground motions were applied to the Franciscan sandstone bedrock, with a Vs $=1220$ $\mathrm{m} / \mathrm{s}$ at a depth of $98 \mathrm{~m}$.

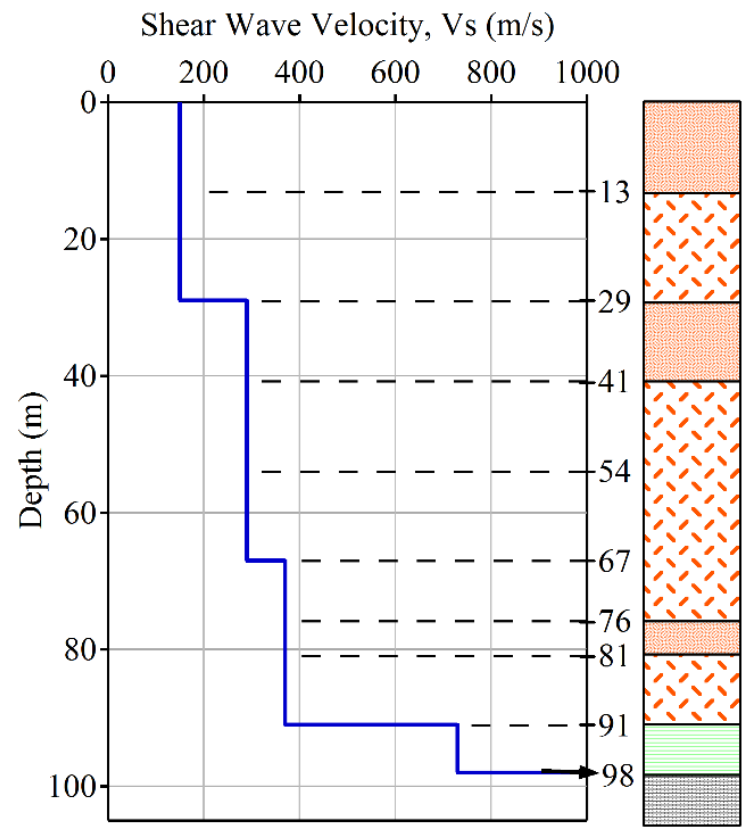

\begin{tabular}{|c|}
\hline \begin{tabular}{|l} 
Layer 1, SW-SM \\
$\quad \gamma_{\mathrm{t}}=18.8 \mathrm{kN} / \mathrm{m}^{3}, \phi^{\prime}=33^{\circ}, \mathrm{Vs}_{\mathrm{s}}=150 \mathrm{~m} / \mathrm{s}$ \\
\end{tabular} \\
\hline $\begin{array}{l}\text { Layer 2, CH (San Francisco Bay Mud) } \\
\quad \gamma_{\mathrm{t}}=17.0 \mathrm{kN} / \mathrm{m}^{3}, \mathrm{~s}_{\mathrm{u}}=59 \mathrm{kPa}, \mathrm{PI}=25, \mathrm{OCR}=1.0, \mathrm{Vs}=150 \mathrm{~m} / \mathrm{s}\end{array}$ \\
\hline \begin{tabular}{|l|l|} 
Layer 3, SM \\
$\quad \gamma_{\mathrm{t}}=18.0 \mathrm{kN} / \mathrm{m}^{3}, \phi^{\prime}=32^{\circ}, \mathrm{Vs}=290 \mathrm{~m} / \mathrm{s}$ \\
\end{tabular} \\
\hline \begin{tabular}{|l} 
Layer 4, CL (Old Bay Clay) \\
$\quad \gamma_{\mathrm{t}}=19.8 \mathrm{kN} / \mathrm{m}^{3}, \mathrm{~s}_{\mathrm{u}}=134 \mathrm{kPa}, \mathrm{PI}=23, \mathrm{OCR}=2.25, \mathrm{Vs}=290 \mathrm{~m} / \mathrm{s}$ \\
\end{tabular} \\
\hline $\begin{array}{l}\text { Layer 5, CL (Old Bay Clay) } \\
\quad \gamma_{\mathrm{t}}=19.8 \mathrm{kN} / \mathrm{m}^{3}, \mathrm{~s}_{\mathrm{u}}=178 \mathrm{kPa}, \mathrm{PI}=23, \mathrm{OCR}=2.25, \mathrm{Vs}=290 \mathrm{~m} / \mathrm{s}\end{array}$ \\
\hline Layer 6, CL (Old Bay Clay), $\gamma_{\mathrm{t}}=19.8 \mathrm{kN} / \mathrm{m}^{3}, \mathrm{~s}_{\mathrm{u}}=216 \mathrm{kPa}, \mathrm{PI}=23$ \\
\hline Layer $7, \mathrm{SW}, \gamma_{\mathrm{t}}=18 \mathrm{kN} / \mathrm{m}^{3}, \phi^{\prime}=39^{\circ}, \mathrm{Vs}=370 \mathrm{~m} / \mathrm{s}$ \\
\hline Layer 8, CL, $\gamma_{\mathrm{t}}=19.8 \mathrm{kN} / \mathrm{m}^{3}, \mathrm{~s}_{\mathrm{u}}=262 \mathrm{kPa}, \mathrm{PI}=23, \mathrm{Vs}=370 \mathrm{~m} / \mathrm{s}$ \\
\hline Layer 9 , Shale, $\gamma_{\mathrm{t}}=21 \mathrm{kN} / \mathrm{m}^{3}, \mathrm{Vs}=730 \mathrm{~m} / \mathrm{s}$ \\
\hline Sandstone, $\gamma_{\mathrm{t}}=23 \mathrm{kN} / \mathrm{m}^{3}, \mathrm{Vs}=1220 \mathrm{~m} / \mathrm{s}$ \\
\hline
\end{tabular}

Figure 4. Shear wave velocity, soil type, and main soil layers for Treasure Island, using data derived from Dickenson [14] and Pass [15]).

\subsection{Ground Motion Selection}

A bedrock (Site Class B) uniform hazard spectrum (UHS) [16] was used to select input motions for the analyses. The UHS was developed from the 2008 United States Geological Survey (USGS) national seismic hazard maps using a probability of exceedance of $2 \%$ in 50 years [17]. Deaggregations for the TI site were performed using the USGS 2008 interactive deaggregation tool [18], which indicates that the seismic hazard for periods ranging from 0.1 to $5 \mathrm{~s}$ is dominated by earthquake events with mean 
magnitudes between 7.0 and 7.7 at distances between 13 and $20 \mathrm{~km}$. Using these magnitude and distance ranges as a guide, a set of 162 possible earthquake time histories were identified from the PEER Strong Motion Database [19]. SigmaSpectra [20,21] was used to select and scale five input ground motions from the assembled set that had spectral shapes similar to the UHS and minimized the sum of squared error across the entire UHS.

The five selected ground motions are presented in Figure 5, which includes the median of the scaled ground motions and the target UHS. These motions were scaled by factors ranging from 5 to 14 . The use of such high scaling factors is required due to the high seismic intensity expected at the site for the $2 \%$ in 50 year UHS motions. Because similar site response results were obtained from each of the input ground motions, subsequent site response comparisons throughout this paper utilize only one of the five input motions, which is identified as ground motion A (GM A). This motion was recorded at the Wonderland station during the 1994 Northridge earthquake $(\mathrm{M}=6.7, \mathrm{R}=15 \mathrm{~km}, \mathrm{RSN} 1011)$.

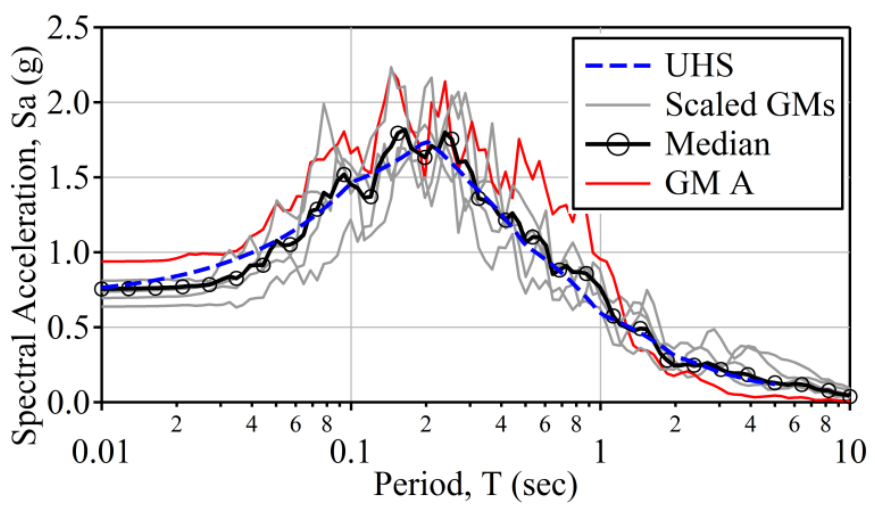

Figure 5. Uniform hazard spectrum (2\% in 50-year probability of exceedance) for the TI site with five scaled input ground motions.

\section{Site Response Results}

The computer program DEEPSOIL v 5.1[12] was used to perform both the EQL and NL site response analyses presented in the subsequent sections. Identical soil models in terms of the shear wave velocity profile and nonlinear shear modulus reduction and damping curves were used for each type of analysis. The NL analyses were performed as total stress analyses, with the nonlinear stress-strain response represented by the modified Kondner-Zelasko (MKZ) hyperbolic-type model that was developed by Matasovic and Vucetic [22]. As noted earlier, the MRDF curve fitting procedure, which utilizes modified Masing rules with a strain-dependent reduction factor [11], was used to model the unload/reload stress-strain response and obtain a better fit to damping curves at large strain. The NL analysis did not incorporate the effects of cyclic degradation or pore pressure generation.

\subsection{Site Response Analyses using Initial Soil Properties}

The initial analyses presented in this section utilized input GM A, the Vs profile in Figure 4, and dynamic soil properties from the Darendeli [1] relationship extended to $10 \%$ shear strain without any consideration for shear strength or a cap on damping. For illustration, the modulus reduction and damping curves for Layer 1 are shown in Figure 3. The acceleration response spectrum of input motion GM A and the associated surface response spectra for the EQL and NL analyses are presented in Figure 6. At most periods the EQL analysis predicts a greater surface response spectrum than the NL analysis, 
with the largest difference occurring at a period of about $1.0 \mathrm{~s}$, where the EQL spectral acceleration is $0.67 \mathrm{~g}$ and the NL spectral acceleration is $0.34 \mathrm{~g}$. Generally speaking, the surface spectra exhibit significant deamplification relative to the input motion at periods less than $2.0 \mathrm{~s}$, with amplification predicted at longer periods. Most notably, the surface response spectra for both EQL and NL analyses, but particularly for NL analyses, are uncharacteristically flat across a wide range of periods, which is atypical for acceleration response spectra recorded at soft soil sites.

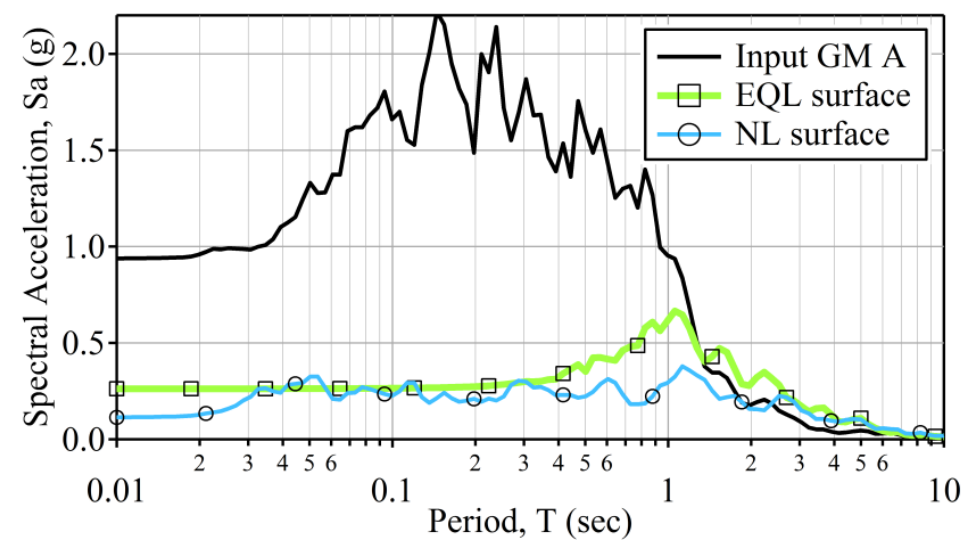

Figure 6. Input acceleration response spectrum along with EQL and NL surface response spectra obtained using the initial dynamic soil properties from Darendeli [1] at the TI site.

The maximum shear strains generated from the initial analyses using input motion GM A are presented in Figure 7. The NL and EQL shear strains are similar over most depths, with maximum shear strains greater than $2.0 \%$ predicted at depths near 10 and $30 \mathrm{~m}$. Nearly every depth has predicted maximum shear strains greater than $0.1 \%$ to $0.2 \%$, which is the threshold above which the results from EQL and NL analyses often begin to diverge and the results from EQL analyses are generally believed to become questionable [23, 24]. At these strain levels, the large damping values used in the EQL analyses result in significant overdamping of high frequencies, which tends to result in significant deamplification and a very flat response spectrum at short periods. Because NL analyses model the fully nonlinear stress-strain response over time during earthquake shaking, this overdamping is believed to be minimized. Interestingly, however, the response spectrum from NL analysis in Figure 6 is also very flat at short periods. 


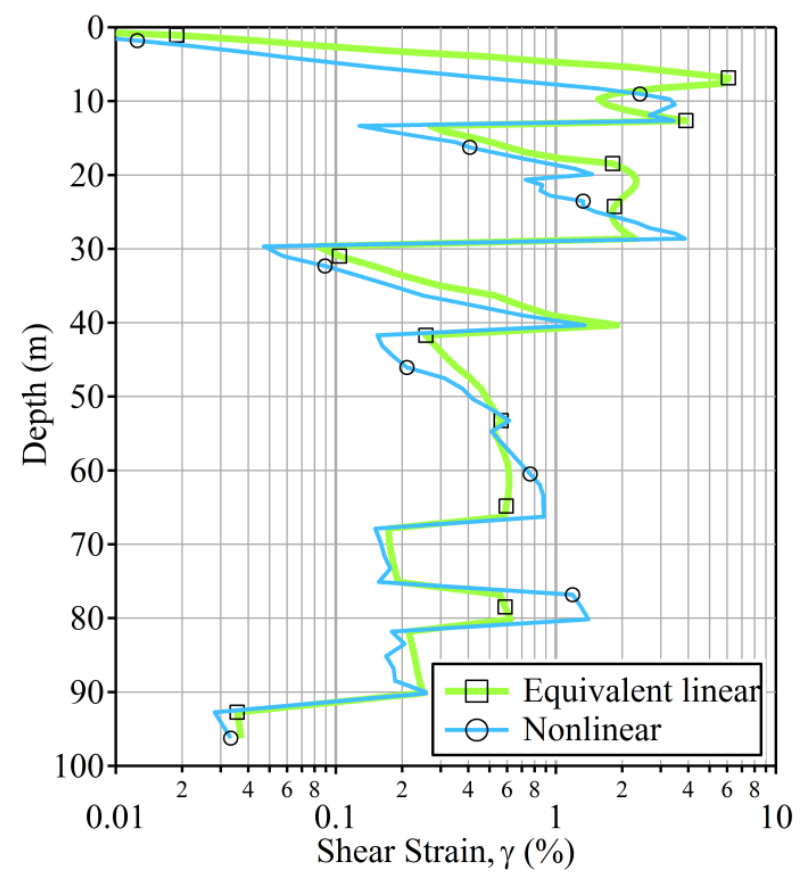

Figure 7. Maximum predicted shear strains from NL and EQL analyses using the initial dynamic soil properties at the TI site

The input acceleration-time history, GM A, and predicted surface time histories from the initial NL and EQL analyses are presented in Figure 8. The peak ground acceleration (PGA) for the input motion is $0.93 \mathrm{~g}$, while the surface PGA is $0.11 \mathrm{~g}$ and $0.26 \mathrm{~g}$ for the NL and EQL analyses, respectively. The NL time history visually includes more high frequency content than the EQL time history, which demonstrates that the high frequencies are less attenuated in the NL analysis despite the fact that the high frequency spectral accelerations from NL analysis are smaller than for EQL analysis. Nonetheless, the predicted NL time history contains some unexpected characteristics, such as vertical jumps in acceleration (e.g., at $\mathrm{t}=5.0 \mathrm{~s}$ ) that are followed by high frequency motion and time periods of near constant acceleration (e.g., $\mathrm{t}=12.5 \mathrm{~s}$ ). The EQL time history does not display these characteristics, but it contains almost no high frequencies.

The frequency content for each of the acceleration time histories was investigated further by examining the Fourier amplitude spectra (FAS), which were smoothed using a log-based triangular window (Figure 9). The EQL and NL motions show amplification of frequencies less than about 0.6 to $0.8 \mathrm{~Hz}$ relative to the input motion, and deamplification at higher frequencies. However, the shapes of the FAS of the EQL and NL motions diverge significantly at frequencies greater than about $1.5 \mathrm{~Hz}$. The EQL FAS decreases in amplitude very quickly, while the NL FAS displays a relatively flat slope that is uncharacteristic of recorded earthquake motions. Furthermore, the NL FAS merges with the input FAS at frequencies greater than $30 \mathrm{~Hz}$, which is not expected due to the anticipated loss of high frequency energy due to the response of this soft soil site.

The flat response spectra at short periods and the unusual characteristics in the time histories and FAS are indications that the initial site response analyses are not producing reliable results for the large shear strains induced in the soil. As a first effort to remedy these problems, the site response analyses were repeated after modifying the dynamic soil properties according to the descriptions outlined in Section 2. 

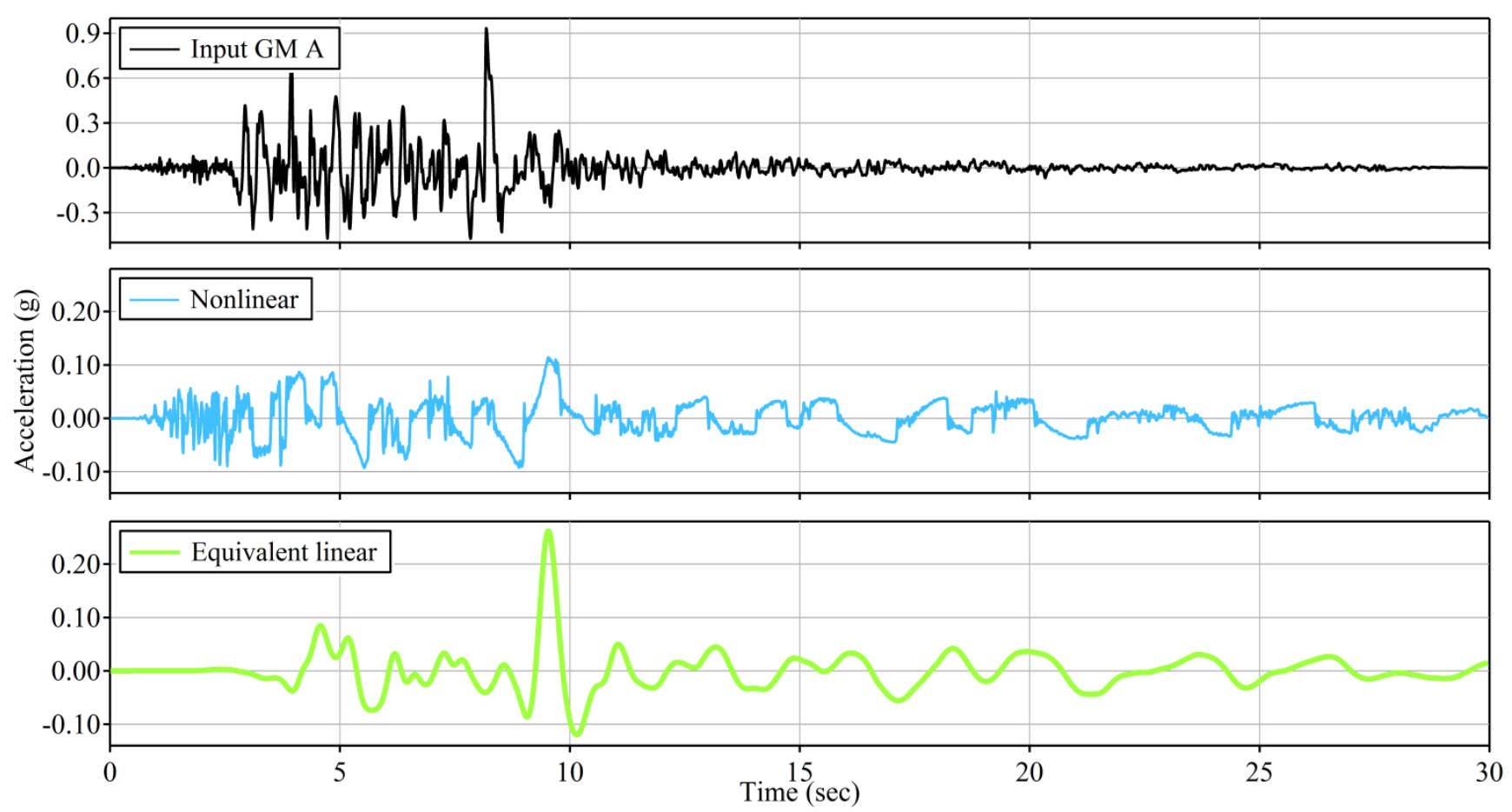

Figure 8. Input acceleration time history along with surface acceleration time histories for the NL and EQL analyses using the initial dynamic soil properties at the TI site.

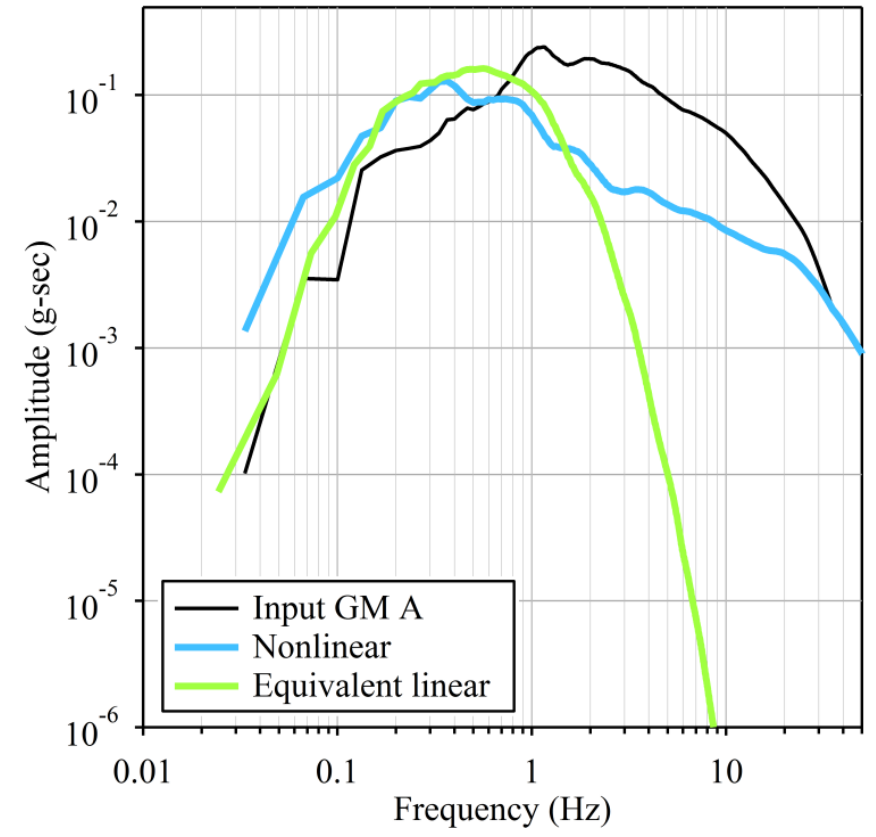

Figure 9. Fourier amplitude spectra for the input motion and the surface motions from NL and EQL analyses using the initial dynamic soil properties at the TI site.

\subsection{Site Response Analyses using Modified Dynamic Soil Properties}

The layers that require modification of their dynamic soil properties are those that experience the largest shear strains. Given the induced shear strains shown in Figure 7, Layers 1 and 2 experience the 
largest shear strains and require modification. However, modifying the properties in these layers alone may simply move the location of largest shear strains to other layers. Therefore, analyses were performed in which the dynamic properties in all layers were modified. The modifications included; 1) modifying the $\mathrm{G} / \mathrm{G}_{\max }$ curve to be consistent with a specified shear strength, and 2) capping the damping curve at $15 \%$.

The surface response spectra from NL and EQL analyses after making modifications to different layers in the sub-surface profile are presented in Figure 10. Modifying only the modulus reduction curves for Layers 1 and 2 to represent an appropriate shear strength generated a significant increase in the surface response spectra. This increase is larger for the EQL analysis than for the NL analysis. Modifying the modulus reduction curve and capping the damping curve at $15 \%$ for Layers 1 and 2 further increased the surface response spectra, but the effect is incrementally much smaller than for modification of the $\mathrm{G} / \mathrm{G}_{\max }$ curve only. Finally, modifying the modulus reduction and damping curves for all layers generated another modest increase in the surface response spectra. At most periods and for both the NL and EQL analyses, the spectral accelerations for the case where the modulus and damping were modified in all layers are nearly double those from the initial case. While these spectra still exhibit relatively flat spectral shapes at periods less than $0.2 \mathrm{~s}$, the spectral shapes are improved relative to the initial scenario, with larger spectral accelerations and pronounced peaks at periods greater than $0.2 \mathrm{~s}$. These characteristics are particularly prominent for the EQL analyses, and in fact, the EQL analysis predicts significantly larger motions than the NL analysis over most periods. The results in Figure 10 show that strength correcting the modulus curves in layers where shear strains exceed $1 \%$ is very important, and should be done at all soft soil sites. Nonetheless, modifying the modulus reduction and damping curves for all layers is viewed as most appropriate if possible.

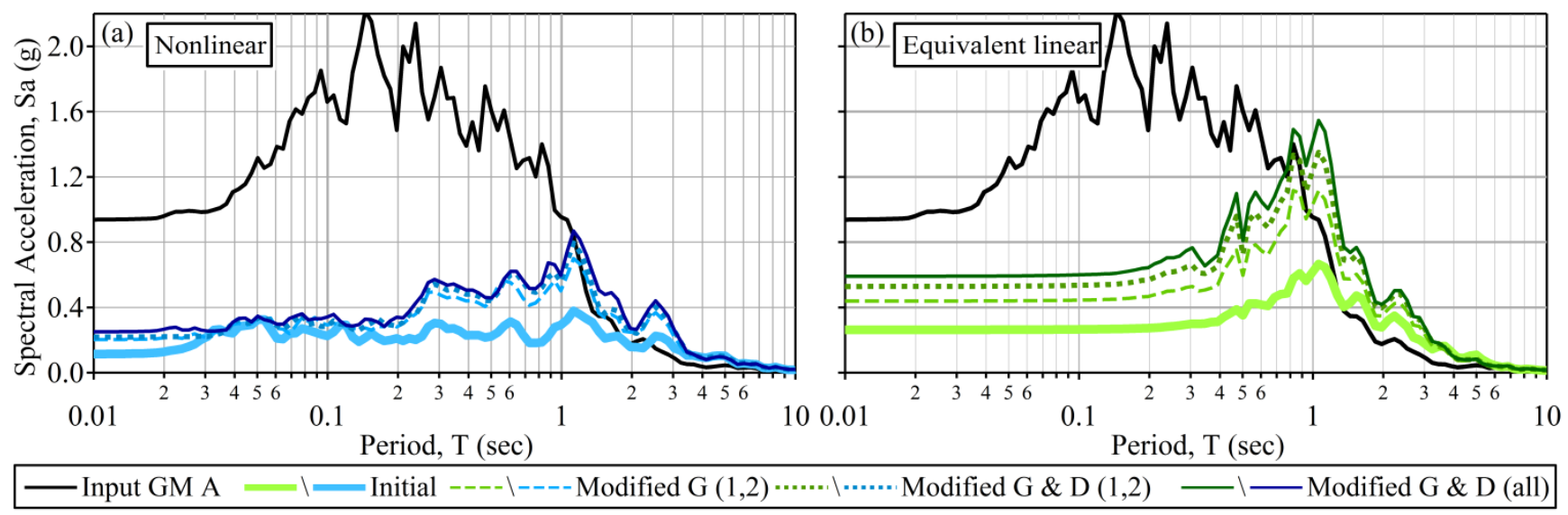

Figure 10. Response spectra for all considered $\mathrm{G} / \mathrm{G}_{\max }$ and $\mathrm{D}$ scenarios for both the (a) nonlinear and (b) equivalent linear analyses at the TI site.

Shear strains predicted for the initial case and the fully-modified case (i.e., strength corrected $\mathrm{G} / \mathrm{G}_{\max }$ and capped $\mathrm{D}$ in all layers) are compared in Figure 11, alongside the Vs profile and soil type. The top two layers of the soil profile exhibit the largest shear strains for both the initial and fully-modified cases. For the NL analyses, the predicted maximum shear strain at a depth of $12 \mathrm{~m}$ was increased from $3.5 \%$ to $5 \%$ after fully-modifying the dynamic soil properties. The opposite trend occurred at a depth of $28 \mathrm{~m}$, where the fully-modified analyses predicted a maximum shear strain of $2 \%$ versus $4 \%$ for the initial analyses. In contrast, the EQL analyses predict only a slight reduction in maximum shear strains in the top two layers when the fully-modified properties are used. As these results show, modifications to the dynamic soil properties have the potential to increase or decrease 
predicted shear strains along the depth of the soil profile because: (1) stiffer layers generally strain less, (2) increases in stiffness may transfer greater seismic energy into overlying layers, resulting in larger shear strains, and (3) stiffening of soil layers may result in greater impedance contrasts which will reflect more seismic energy back down into underlying layers.

Figure 12 shows the surface time histories from the analyses with the initial and fully-modified properties. The increased shear stiffness associated with the fully-modified cases yielded increased amplitudes and more high frequency content of the surface time histories for both NL and EQL analyses. The fully-modified NL time history still displays some near vertical jumps, as well as some near constant accelerations (i.e. $\mathrm{t}=12.5 \mathrm{~s}$ ), but these characteristics are less severe than for the initial analysis. A better idea of the frequency content of the computed surface motions can be obtained by examination of the FAS (Figure 13). At frequencies greater than about $0.3 \mathrm{~Hz}$, the fully-modified cases have larger amplitudes than the initial cases for both the NL and EQL analyses. Nonetheless, the FAS for the fully-modified NL analysis still exhibits a flat, almost log-linear decrease in amplitude at frequencies greater than $0.5 \mathrm{~Hz}$. As noted above, this is an uncharacteristic spectral shape not observed in actual recorded ground motions.
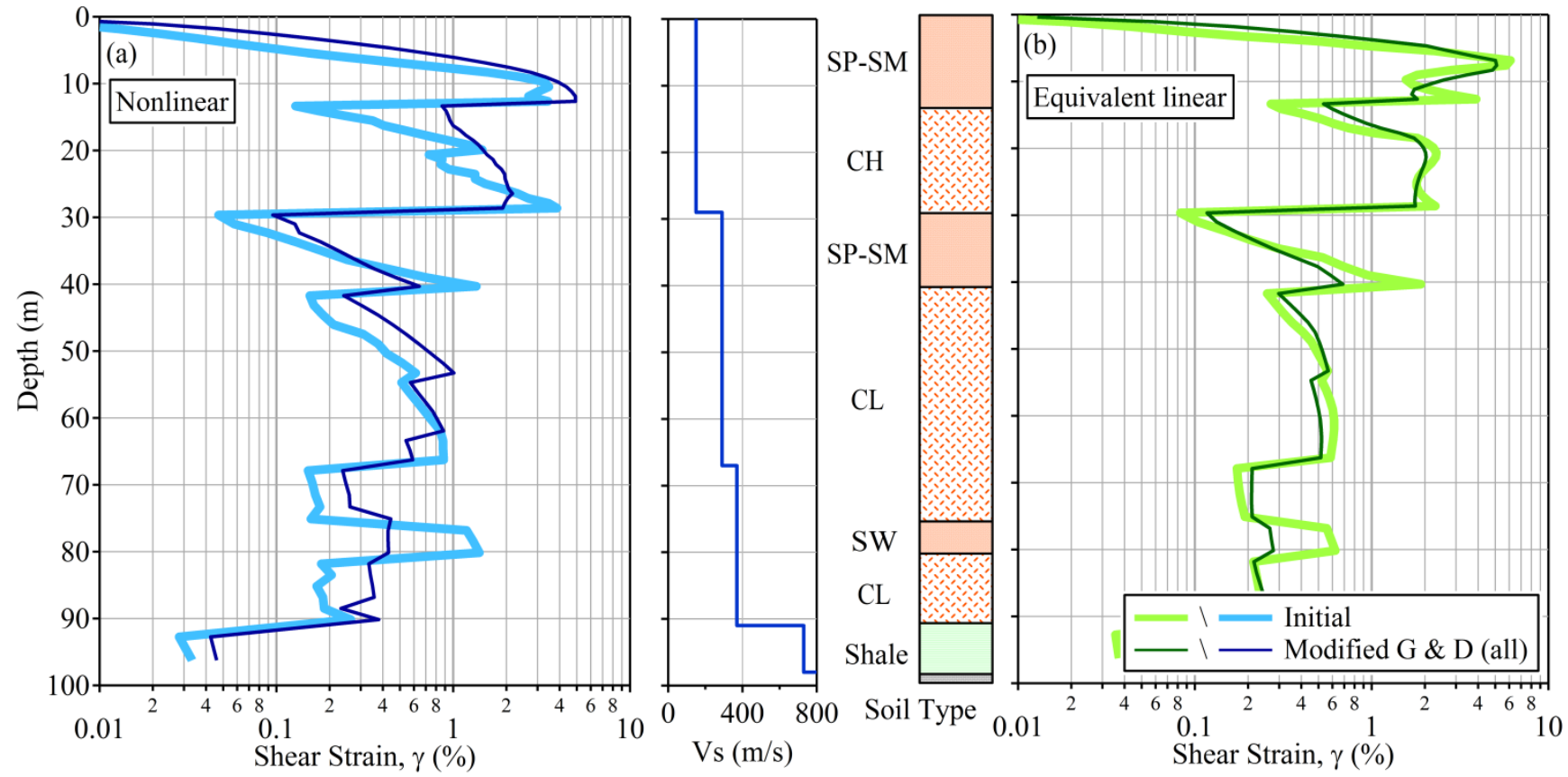

Figure 11. Maximum predicted shear strain profiles for the initial and fully modified $G / G_{\max }$ and D scenarios for the (a) nonlinear and (b) equivalent linear analyses, with the shear wave velocity profile and soil type for the TI site. 


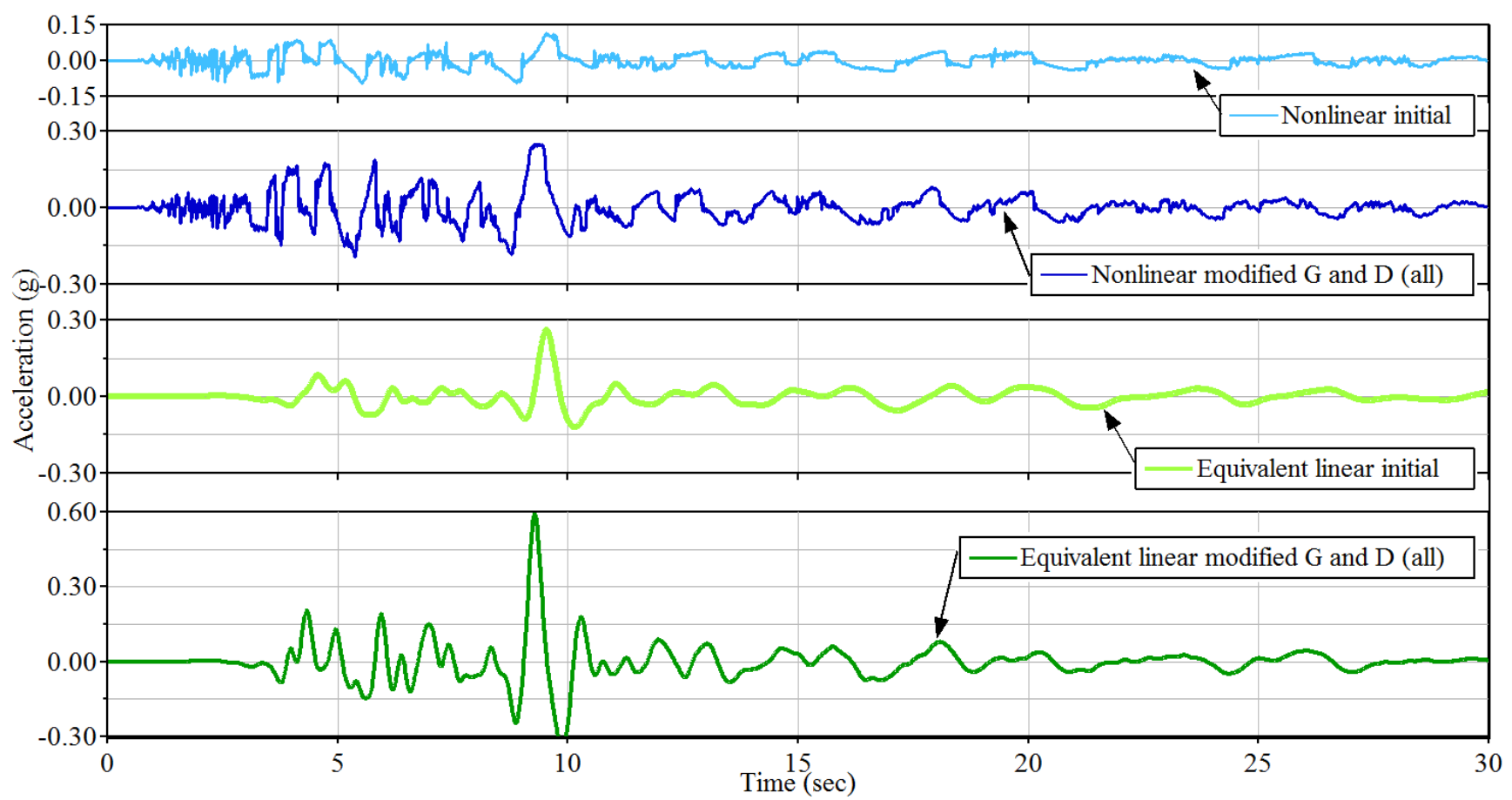

Figure 12. Predicted surface acceleration time histories of the initial and fully-modified cases for NL and $\mathrm{EQL}$ analyses for the TI site.

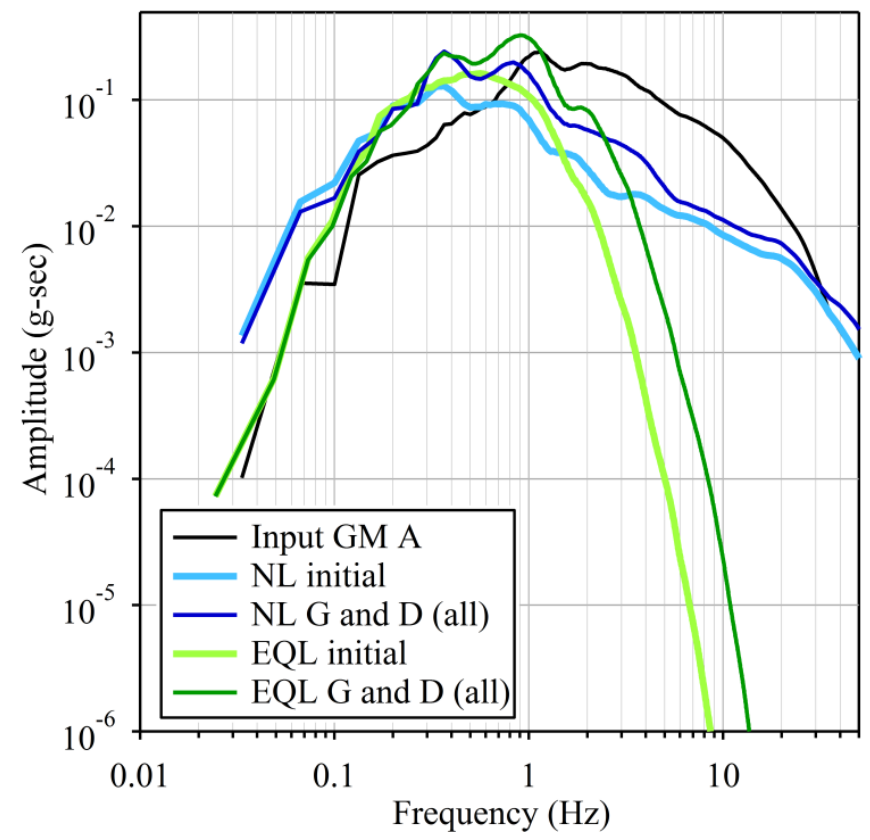

Figure 13. Fourier amplitude spectra of the initial and fully-modified cases for the NL and EQL analyses at the TI site. 


\section{Comparisons with High-Intensity Motions Recorded at Soft Soil Sites}

As a means to qualitatively assess the results of the NL and EQL site response analyses presented above, the expected frequency content of high-intensity surface ground motions at soft soil sites was investigated via comparisons with recorded ground motions. The recorded ground motions selected for comparison were obtained from the PEER NGA-West2 strong ground motion database (http://ngawest2.berkeley.edu/) by searching for sites with an average shear wave velocity over the top 30 meters $\left(\mathrm{V}_{\mathrm{s} 30}\right)<200 \mathrm{~m} / \mathrm{s}$, for recorded moment magnitude earthquakes $>7.0$ and at Joyner-Boore distances $<20 \mathrm{~km}$. Six recordings fit these criteria; four from the $2010 \mathrm{M}_{\mathrm{w}} 7.0$ Darfield, New Zealand Earthquake and two from the $2010 \mathrm{M}_{\mathrm{w}}$ 7.0 El Mayor-Cucapah, Mexico Earthquake. One recording from each earthquake was chosen for qualitative comparison with the site response results presented above. These recordings are the El Centro Array \#12 recording (Vs30 of $197 \mathrm{~m} / \mathrm{s}$ ) from the El Mayor-Cucapah earthquake and the Christchurch Resthaven recording (Vs30 of $141 \mathrm{~m} / \mathrm{s}$ ) from the Darfield earthquake. At El Centro Array \#12 the north-south (NS) component recorded a PGA of 0.33 g, while the east-west (EW) component recorded a PGA of $0.4 \mathrm{~g}$. At Christchurch Resthaven the NS component recorded a PGA of $0.26 \mathrm{~g}$, while the EW component recorded a PGA of $0.24 \mathrm{~g}$. At both sites the NS components were chosen arbitrarily and are used in the comparison plots below. These two sites have Vs30 values that bracket the $\mathrm{Vs}_{30}$ of $152 \mathrm{~m} / \mathrm{s}$ for the TI site, and since they were recorded at relatively close distances to large magnitude earthquakes they likely experienced high-intensity input (i.e., rock) ground motions and significant nonlinear soil behavior.

Thirty second intervals of the surface time histories from the Christchurch Resthaven and El Centro Array \#12 recordings are presented in Figure 14, along with the surface time histories resulting from the fully-modified EQL and NL site response analyses at TI. A qualitative comparison reveals that neither of the high intensity recorded time histories portray the unusual features observed in the acceleration time histories from the NL analyses. Furthermore, both recorded time histories have more high-frequency content than the predicted time histories for TI, particularly when compared with the lack of high frequencies in the time history from the EQL analysis.

FAS for each of the four time histories are compared in Figure 15. Each FAS has been normalized with respect to its largest Fourier amplitude so that the relative shapes of the FAS can be examined. Both of the FAS from the recorded ground motions have distinct cutoff frequencies at approximately 3-5 Hz, above which the amplitude rapidly decays. This sharp decrease in Fourier amplitude is typical of surface time histories recorded during earthquakes and is often modeled using the spectral decay parameter known as kappa $(\kappa)$ [25] and an exponential function, exp $(-\pi \cdot \kappa \cdot f)$. In this equation, larger values of kappa generate a more rapid decay of amplitude with increasing frequency. Kilb et al. [26] reported typical kappa values that ranged from 0.005 s to $0.1 \mathrm{~s}$, while Campbell [27] reported that rock motions in Western North America commonly yield kappa values around $0.04 \mathrm{~s}$. Generally, kappa increases as the shear wave velocity of the subsurface materials decrease and the depth of sediments increase [28, 29]. For kappa values derived from surface recordings, almost all values are smaller than $\kappa=0.1 \mathrm{~s}$ [28]. Included in Figure 15 is the theoretical decay of the FAS at high frequencies associated with kappa values of $0.03 \mathrm{~s}$ and $0.1 \mathrm{~s}$. These values bracket the observed spectral decay in the recorded motions. In contrast to the recorded ground motions and the theoretical kappa models, neither the EQL nor NL site response results follow the established pattern of high-frequency decay. Both site response results indicate lower than expected cutoff frequencies of approximately $1.0 \mathrm{~Hz}$. The FAS from the EQL analysis decays much too rapidly, with an estimated kappa value equal to $0.3 \mathrm{~s}$. This value of kappa was estimated from the approximately linear slope of the log (FAS) vs. frequency plot (Figure 15b) using the method of Anderson and Hough [25]. As noted above, a kappa value of $0.1 \mathrm{~s}$ is 
approximately an upper bound as derived from recorded ground motions. Thus, a value of $0.3 \mathrm{~s}$ for the EQL approach clearly indicates overdamping of the high frequency response. The high frequency decay in the FAS from the NL analysis is very irregular and does not fit the kappa model.

The results in Figure 14 and 15 demonstrate that unresolved issues remain when performing site response analyses at soft soil sites for high-intensity motions commonly required for design events. Although accounting for more realistic estimates of soil shear strength in the modulus reduction curves and capping damping can improve the computed surface response for these cases, the shapes of the time histories, FAS and acceleration response spectra still remain uncharacteristic when compared with recorded ground motions. EQL analysis tends to overdamp the high frequencies and produce unrealistically large kappa values compared with those associated with recorded motions at soft soil sites. NL analysis produces motions with more high frequency content, but the spectral shape at high frequencies is not consistent with seismological theory and the computed surface acceleration-time histories contain some unrealistic characteristics. Additional research is needed to improve the prediction of site response using both EQL and NL analyses at soft sites for high-intensity input motions.

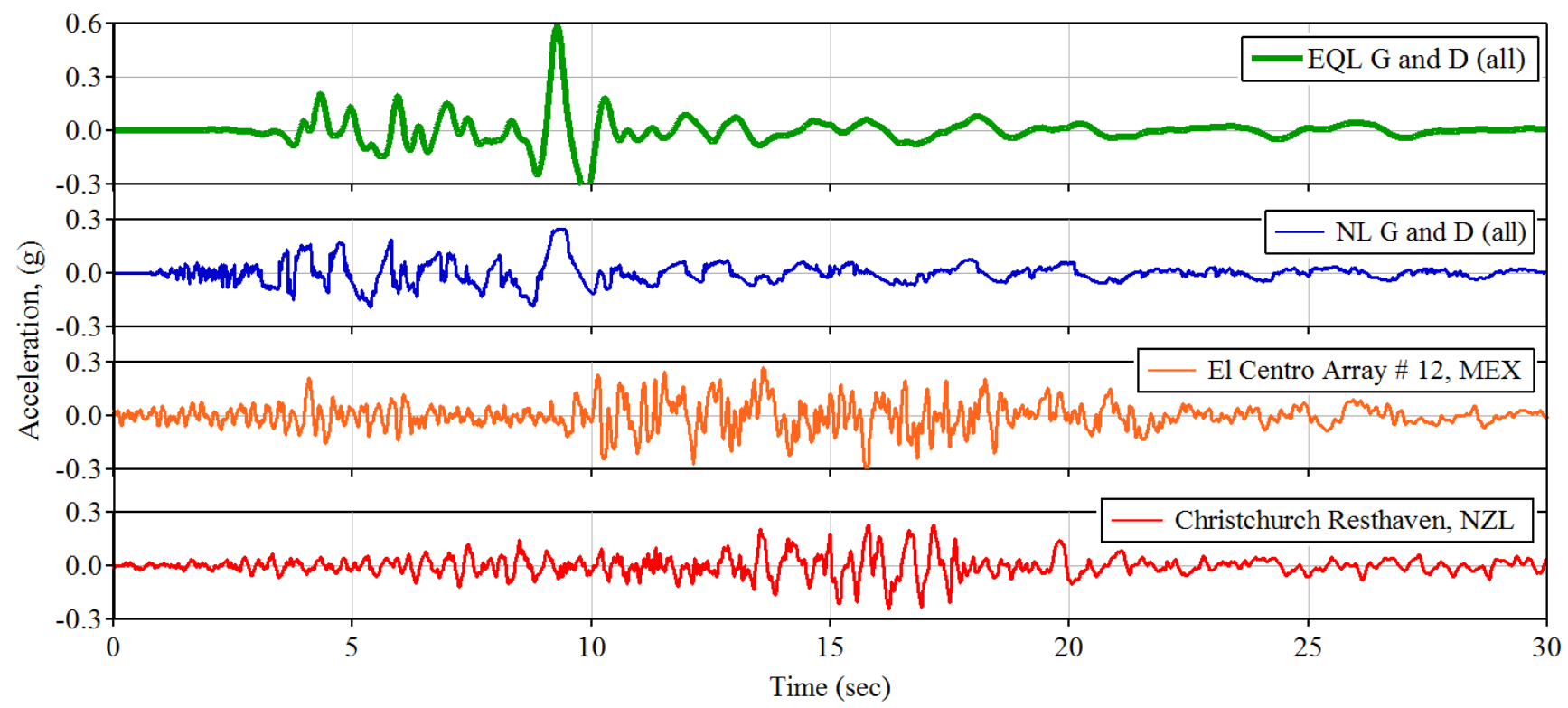

Figure 14. Acceleration time histories for the EQL and NL fully-modified site response analyses at the TI site along with recorded time histories from two soft soil sites that recorded high-intensity ground motions during previous earthquakes. 

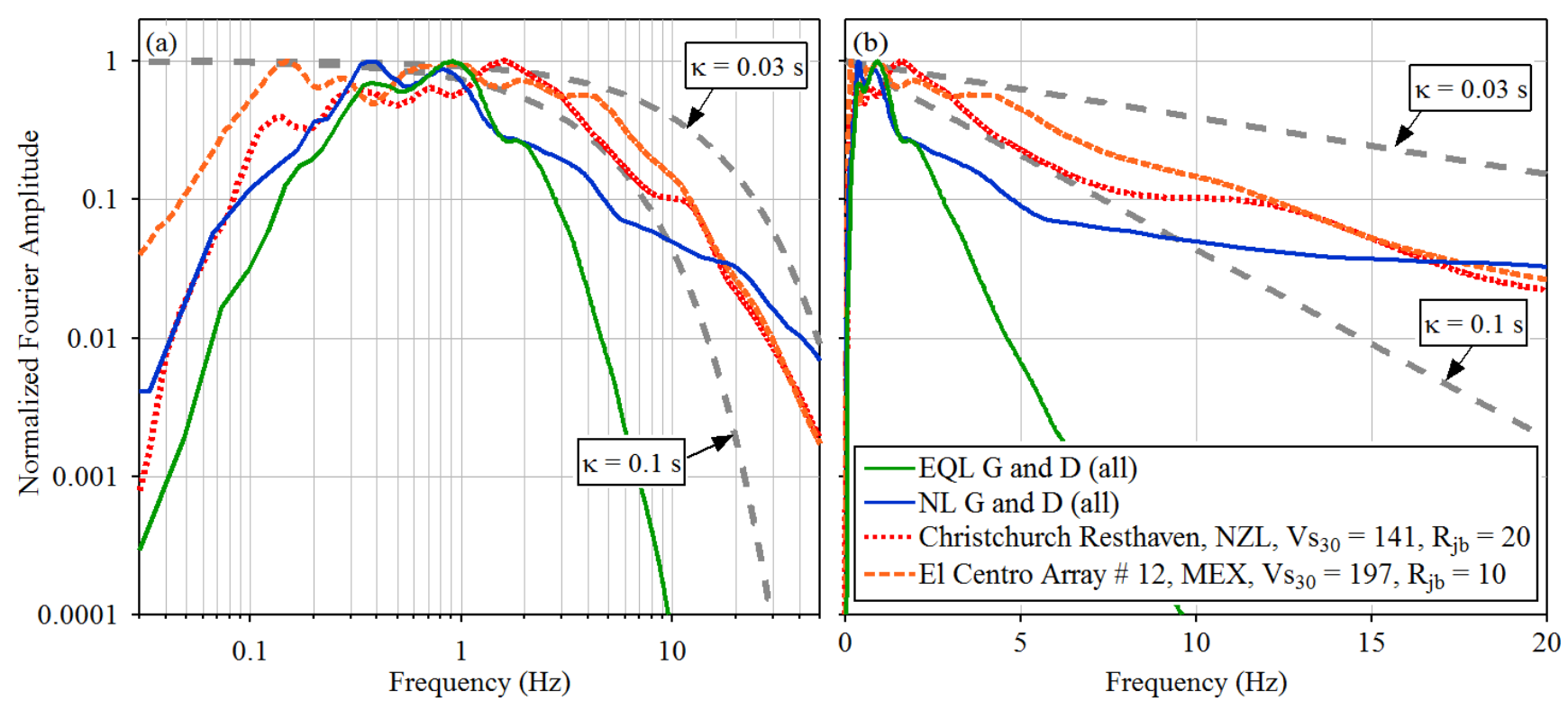

Figure 15. Normalized Fourier amplitude spectra for the EQL and NL fully-modified site response analyses at the TI site along with recorded time histories from two soft soil sites that recorded high-

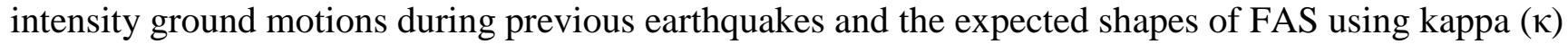
values of 0.03 and $0.1 \mathrm{~s}$.

\section{Conclusions}

In this study, 1D site response analyses have been performed at Treasure Island, a well-known soft soil site near several major active faults, in an attempt to illustrate challenges associated with developing realistic surface ground motions for soft soil sites subject to high-intensity input ground motions commonly required for seismic design. The high-intensity input ground motions were developed by scaling time histories to a target UHS, which was developed using a $2 \%$ probability of exceedance in 50 years. Both EQL and NL site response analyses, with identical shear wave velocity profiles and nonlinear $\mathrm{G} / \mathrm{G}_{\max }$ and $\mathrm{D}$ curves, were performed using the computer program DEEPSOIL [12]. G/G $\mathrm{G}_{\max }$ curves at large shear strains were strength corrected to better match the estimated static shear strength of the soil according to the fitting procedure proposed by Hashash et al. [8]. Additionally, damping at large shear strains was capped at $15 \%$. Modifying $\mathrm{G} / \mathrm{G}_{\max }$ in the layers with the greatest predicted shear strains had a more significant impact on the amplitude and shape of the surface time histories and response spectra than any further modifications to $\mathrm{G} / \mathrm{G}_{\max }$ or $\mathrm{D}$. Nonetheless, modifications to the modulus reduction and damping curves for all layers within a soft soil model should be investigated to ensure that realistic shear strengths are modeled and excessive damping values are not utilized. One can observe the impact of making these modifications by examining the predicted surface acceleration time histories and FAS to make sure they look appropriate and/or better than those obtained without modifications.

Even after fully-modifying dynamic soil properties in all layers, the site response results at Treasure Island qualitatively appeared to be uncharacteristic relative to ground motions recorded at soft soil sites subjected to high-intensity input rock motions. This is true for both EQL and NL analyses. Specifically, the spectral shapes of surface ground motions predicted by EQL analyses appear to have unrealistically high kappa values, while those predicted by NL analyses do not resemble any typical kappa relationship. Therefore, future work should focus on improvements to current EQL and NL site 
response models to better predict the high frequency characteristics of earthquake shaking for soft soil sites subject to high-intensity input motions and to preserve realistic acceleration time histories and spectral shapes.

Although it is commonly believed that NL site response analyses provide more realistic estimates of site response at large strains, and in particular predict larger amplification at short periods, this study shows that predicted short period amplification from EQL analyses can be larger than from NL analyses. In fact, EQL analyses actually produced spectral accelerations that were approximately twice as large as the NL values across all periods at the Treasure Island site. Therefore, until the issues associated with modeling large shear strains are resolved, caution should be exercised in simply assuming that NL analyses will provide the most realistic/conservative estimates of site response at soft soil sites.

\section{Acknowledgements}

This work was supported primarily by U.S. National Science Foundation (NSF) grant CMMI1261775. However, any opinions, findings, and conclusions or recommendations expressed in this material are those of the authors and do not necessarily reflect the views of NSF.

\section{References}

[1] Darendeli, M. (2001). "Development of a New Family of Normalized Modulus Reduction and Material Damping Curves," Ph.D. Dissertation, University of Texas at Austin. Austin, TX.

[2] Seed, H. and Idriss, I. (1970). "Soil Moduli and Damping Factors for Dynamic Response Analyses," Report No. EERC-70-10, Earthquake Engineering Research Center, University of California, Berkeley, CA.

[3] Hardin, B.O., and Drnevich, V.P. (1972). "Shear Modulus and Damping in Soils: Measurement and Parameter Effects". Journal of the Soil Mechanics and Foundations Division, Proceedings of the American Society of Civil Engineers, Vol. 98, No. SM6, pp. 603-624.

[4] Electric Power Research Institute, EPRI (1993). “Guidelines for Determining Design Basis Ground Motions". Report No. EPRI TR-102293, Palo Alto, CA.

[5] Vucetic, M., and Dobry, R. (1991). "Effect of Soil Plasticity on Cyclic Response". Journal of Geotechnical Engineering, Vol. 117, No. 1, pp. 89-107.

[6] Stewart, J.P., and Kwok, A.O.L. (2008). "Nonlinear Seismic Ground Response Analysis: Code Usage Protocols and Verification against Vertical Array Data." Proc., ASCE conference of Geotechnical Earthquake Engineering and Soil Dynamics IV, Geotechnical Special Publication 181, ASCE, Sacramento, CA.

[7] Yee, E., Stewart, J.P., and Tokimatsu, K. (2013) "Elastic and large-strain nonlinear seismic site response from analysis of vertical array recordings" Journal of Geotechnical and Geoenvironmental Engineering, Vol. 139, No. 10.

[8] Hashash, Y.M.A., Phillips, C., and Groholski., D.R. (2010). "Recent Advances in Non-linear Site Response Analysis." Proc., $5^{\text {th }}$ International Conf. on Recent Advances in Geotechnical Earthquake Engineering and Soil Dynamics, NEES, San Diego, CA.

[9] Menq, F. Y. (2003) "Dynamic Properties of Sandy and Gravelly Soils," Ph.D. Dissertation, University of Texas at Austin. Austin, TX. 
[10] Chiu, P., Pradel, D.E., Kwok, A.O., Stewart, J.P. (2008). "Seismic Response Analyses for the Silicon Valley Rapid Transit Project." Proc., ASCE conference of Geotechnical Earthquake Engineering and Soil Dynamics IV, Geotechnical Special Publication 181, ASCE, Sacramento, CA.

[11] Phillips, C., and Hashash, Y.M.A. (2009). "Damping Formulation for Non-linear Site Response Analyses." Soil Dynamics and Earthquake Engineering. Vol., 29, pp. 1143-1158.

[12] Hashash, Y.M.A., Groholski, D.R., Phillips, C.A., Park, D, and Musgrove, M. (2012) "DEEPSOIL 5.1, User Manual and Tutorial." pp. 107.

[13] Hsu, C., and Vucetic, M. (2002). "Dynamic and Cyclic Behavior of Soils Over a Wide Range of Shear Strains in NGI-type Simple Shear Testing Devices," Research Report UCLA ENG-02-228, Univ. of California, Los Angeles.

[14] Dickenson, S.E. (1994). "Dynamic Response of Soft and Deep Cohesive Soils During the Loma Prieta Earthquake of October 14, 1989". Ph.D. thesis, University of California, Berkeley, p. 331.

[15] Pass, D.E. (1994). "Soil Characterization of the Deep Accelerometer Site at Treasure Island, SanFrancisco, California". M.S. thesis, University of New Hampshire, Durham, NH.

[16] American Society of Civil Engineers (2010). "Minimum Design Loads for Buildings and Other Structures". ASCE Standard ASCE/SEI 7-10, American Society of Civil Engineers, Reston, Virgina.

[17] United States Geological Survey (USGS), (2008). "National Seismic Hazard Maps: Documentation," USGS Open File Report 2008-1128.

[18] United Sates Geological Survey (USGS), (2008). 2008 Interactive Deaggregations, <http://geohazards.usgs.gov/deaggint/2008/>, (Jan 9, 2013).

[19] Pacific Earthquake Engineering Research Center, PEER (2011). "Users Manual for the PEER Ground Motions Database Web Application" The Peer Center, University of California, Berkeley, CA. http://peer.berkeley.edu/peer_ground_motion_database/site.

[20] Kottke, A. and Rathje, E. (2013) "SigmaSpectra," <http://nees.org/resources/sigmaspectra>.

[21] Kottke, A. and Rathje, E.M. (2008). "A Semi-Automated Procedure for Selection and Scaling of Recorded Earthquake Motions for Dynamic Analysis" Earthquake Spectra, Earthquake Engineering Research Institute, Vol. ,24, No. 4, pp. 911-932.

[22] Matasovic, N. and Vucetic, M. (1993) "Cyclic Characterization of Liquefiable Sands". ASCE Journal of Geotechnical Engineering, Vol. 119, No. 11, pp. 1805-1822.

[23] Matasovic, N. and Hashash, Y. (2012) "Practices and Procedures for Site-Specific Evaluations of Earthquake Ground Motions" National Cooperative Highway Research Program, Synthesis 428, a Synthesis of Highway Practice, Transportation Research Board, Washington, D.C.

[24] Kaklamanos, J., Bradley, B.A., Thompson, E.M., and Baise, L.G. (2013) "Critical Parameters Affecting Bias and Variability in Site-Response Analyses Using Kik-net Downhole Array Data". Bulletin of the Seismological Society of America, Vol. 103, No. 3. pp. 1733-1749.

[25] Anderson, J.G., and Hough, S.E. (1984). "A Model for the Shape of the Fourier Amplitude Spectrum of Acceleration at High Frequencies." Bulletin of the Seismological Society of America. Vol., 74, No. 5, pp. 1969-1993.

[26] Kilb, D., Biasi, G., Anderson, J., Brune, J., Peng, Z., and Vernon, F. (2012). “A Comparison of the Spectral Parameter Kappa from Small and Moderate Earthquakes Using Southern California ANZA Seismic Network Data." Bulletin of the Seismological Society of America. Vol., 102, No. 1, pp. 284-300. 
[27] Campbell, K.W. (2003). "Prediction of Strong Ground Motion Using the Hybrid Empirical Method and Its Use in the Development of the Ground-Motion (Attenuation) Relations in Eastern North America". Bulletin of the Seismological Society of America, Vol., 93, No. 3, pp. 1012-1033.

[28] Van Houtte, C., Drouet, S., and Cotton, G. (2011) "Analysis of the Origins of $\kappa$ (Kappa) to Compute Hard Rock to Rock Adjustment Factors for GMPEs". Bulletin of the Seismological Society of America, Vol., 101, No. 6, pp. 2926-2941.

[29] Campbell, K.W. (2009). "Estimates of Shear-Wave Q and $\kappa_{0}$ for Unconsolidated and Semiconsolidated Sediments in Eastern North America". Bulletin of the Seismological Society of America, Vol., 99, No. 4, pp. 2365-2392. 